\title{
Research on Operating Efficiency of Government Industry Guidance Fund
}

\author{
Yifei Gong, Peiyue Li, Ziqiao Shen \\ College of Economic and Management, Southwest University, Chongqing, China \\ Email: gyifei@swu.edu.cn
}

How to cite this paper: Gong, Y.F., Li, P.Y. and Shen, Z.Q. (2020) Research on Operating Efficiency of Government Industry Guidance Fund. Theoretical Economics Letters, 10, 90-101. https://doi.org/10.4236/tel.2020.101006

Received: December 19, 2019

Accepted: January 28, 2020

Published: February 4, 2020

Copyright $\odot 2020$ by author(s) and Scientific Research Publishing Inc. This work is licensed under the Creative Commons Attribution International License (CC BY 4.0).

http://creativecommons.org/licenses/by/4.0/

(c) (i) Open Access

\begin{abstract}
In the process of deepening the reform of the economic system, the government has set up the industry guidance fund based on the industry and guided more social capital to participate in the market-oriented construction, which has become a powerful measure to stimulate economic growth and promote regional economic development. Starting from the current situation and development trend of the industry guidance fund, this paper studies with the development model and policy effect of the government industry guidance fund, analyzes the problems existing in the operation process, and puts forward relevant policy suggestions to provide reference for the development of the government industry guidance fund.
\end{abstract}

\section{Keywords}

Industry Guidance Fund, Development Model, Policy Effect, Operation Problems

\section{Research Background}

Accelerating the development of government industry guidance fund is an important policy measure to implement the reformation of the supply side and deepen it. At the same time, it promotes the important transformation from the management-oriented government to the service-oriented government, and further improves the financial governance ability and the utilization efficiency and economic benefit of financial funds.

According to the statistics of China Venture [1], by the end of June 2019, 1311 government guidance funds had been set up in China, with a total fund target size of 10.12 trillion yuan and a total scale 19,694 trillion yuan (see Figure 1). During 2012-2018, the number of funds has increased by 1092 and the total scale of the establishment of funds has increased by 1878.5 billion yuan. The government 


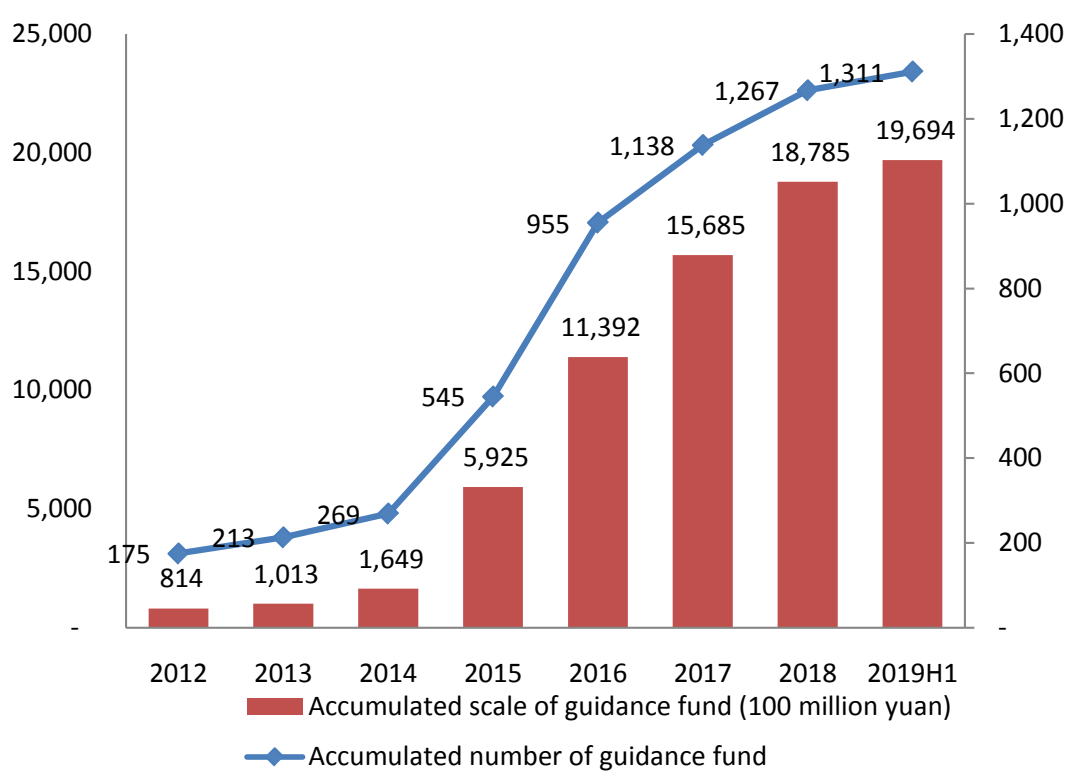

Figure 1. The establishment of guidance fund of Chinese government from 2008 to 2019 $\mathrm{H} 1^{1}$.

industry guidance fund plays a great role in supporting specific industries, especially the national industry guidance fund, which will play a leading role in demonstration and fully drive the development of social capital driven industries. As of the first half of 2019, 966 industry government guidance funds have been established, counting for $57.3 \%$ of the total funds (see Figure 2).

At present, China's established industry funds mainly focus on "Made in China 2025" and seven strategic emerging industries, including energy conservation and environmental protection, emerging information industry, biological industry, new energy, new energy vehicles, high-end equipment manufacturing industry and new materials (see Figure 3).

After the climax of large-scale establishment of government guidance funds for many years, the pace of provinces and cities in the pursuit of guidance fund scale has gradually slowed down. Under the current operation mode, the development of the guidance fund of the local governments is uneven, and there are many common problems. Based on the introduction of the main organizational forms of the domestic government industrial guidance fund, this paper discusses the guiding effect of the government industrial guidance fund, and further investigates the existing problems of the government industrial guidance fund in China, and draws relevant policy recommendations.

\section{Development Models of Industry Guidance Fund}

There are three common models of guidance fund, which are equity investment model, follow-up investment model and financing guarantee model [2]. In addition, the less commonly used models include investment guarantee model and risk subsidy model. However, in the actual operation of the guidance fund, the ${ }^{1}$ Source: https://www.pedata.cn/. 


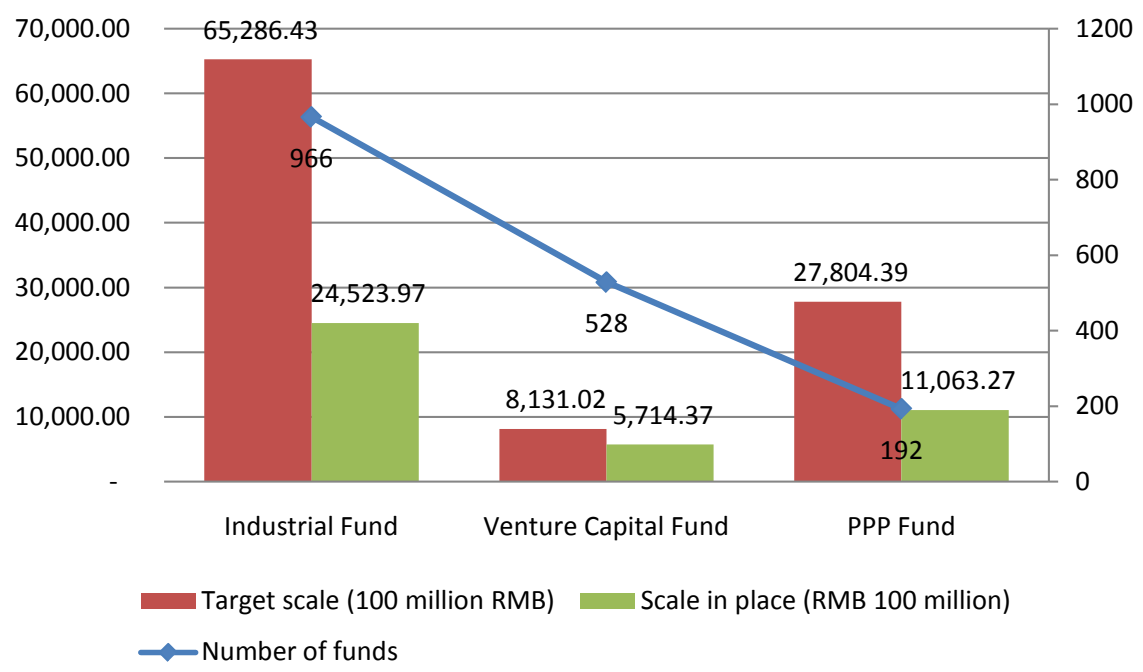

Figure 2. Distribution of types of Chinese government guidance funds as of $2019 \mathrm{H}^{2}$.

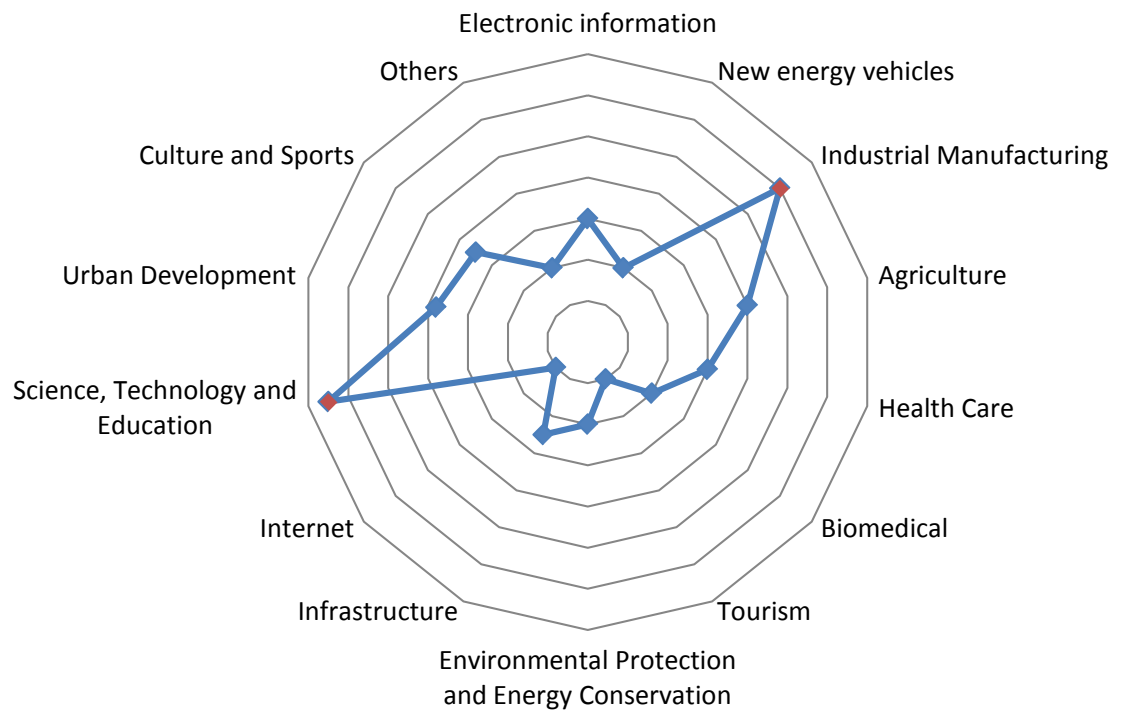

Figure 3. Industry distribution of industry guidance fund ${ }^{3}$.

most commonly used model is equity investment model, followed by follow-up investment model.

\subsection{Equity Investment Model}

The equity investment model refers to the guidance fund as a fund of funds to contribute and establish a sub-fund with social capital in the form of equity participation. The sub-fund completes the investment decision and daily management according to the policy guidance, and withdraws within the agreed time limit. As the daily operation of the sub fund is in the charge of the fund manager, the equity investment is easy to operate and highly market-oriented for the guidance fund. The guiding effect of the government in this process has been ${ }^{2}$ Source: https://www.pedata.cn/, https://www.wind.com.cn/.

${ }^{3}$ Source: http://www.stats.gov.cn/. 
brought into full play.

\subsection{Follow-up Investment Model}

The follow-up investment is a joint investment way. First, the guidance fund needs to be closely combined with innovation technology projects or enterprises. For investment institutions, after investment projects are determined, they have the right to apply for real-time follow-up of the operation of the funds. It should be noted that this way is the only direct investment way in the guidance fund models, so the industry-oriented performance is strong. In addition, in this way, the sustainability of capital operation can be improved.

\subsection{Financing Guarantee Model}

In the specific operation, financing guarantee can be divided into two ways: direct and indirect. Direct compensation refers to the way that the government adopts direct compensation funds for enterprises with good credit according to the credit degree of investment enterprises, while indirect compensation is mainly to compensate the guarantee institutions introduced by the government.

\subsection{Other Models}

In other models, risk subsidy and investment guarantee are free of charge. The risk subsidy is to properly protect the interests of investment institutions. Under the guidance of the fund, investment institutions will receive certain subsidies after completing the investment in the start-up SEMs. The investment guarantee model is mainly to compensate those selected enterprises, and the form of guarantee is to carry out direct subsidy in the early stage and follow-up investment.

As shown in Table 1, there are some differences in the characteristics of various models, so it is necessary to select the most appropriate model in combination with the actual situation of the project when selecting, and Combined with the analysis of the current situation in China, the bond market is in the stage of perfection, so the use of financing guarantee model has some difficulties, so the equity investment model has become the main choice, but after the social credit system has been perfected, the financing guarantee model will become an inevitable choice.

Table 1. Comparison of development models of industry guidance funds.

\begin{tabular}{ccc}
\hline Item & Main Features & Target Group \\
\hline Equity Investment & Low profit and sustainable operation & $\begin{array}{c}\text { Seed stage/Initial stage/Emerging } \\
\text { industries }\end{array}$ \\
Follow-up Investment & Low profit and sustainable operation & Initial stage \\
Financing Guarantee & Low profit and sustainable operation & Growing stage \\
Investment Guarantee & One-time free support & Seed stage/Initial stage \\
Risk Subsidy & One-time free support & Initial stage
\end{tabular}




\section{Analysis of the Policy Effect of Industry Guidance Fund}

This paper will study the policy effect of industry guidance fund by analyzing the leverage effect of industry guidance fund and promoting the adjustment of industry structure.

\subsection{Leverage Effect}

Industry guidance fund can play the leverage effect of financial funds, leverage social capital, effectively integrate financial funds and social capital, attract more bank capital, insurance capital and other social capital with less funds, and lead social capital to areas that need to be developed, so as to achieve the goal of industry guidance funds [3]. Some emerging frontier industries often have greater risks, especially policy risks. The involvement of the fund is conducive to reducing the policy risks of investment projects, because the government is willing to invest financial capital in a specific industry, it means that the industry is definitely supported by the government, and may receive more policy support in the future. In addition to the huge amount of social capital that it uses financial funds to leverage, the government will also cooperate with the use of "enterprise subsidies" and "supporting policies" to maximize the leverage effect.

\subsection{Adjustment of the Industrial Structure}

The purpose of setting up the industry guidance fund is to introduce more capital into the development of emerging, key and strategic industries and the upgrading of traditional industries, so as to promote the optimization and upgrading of China's industrial structure [4]. When choosing investment objects, the high-quality enterprises with great potential, advanced technology, strong competitiveness and high efficiency are generally selected [5]. As a result of this choice, good resources and capital will be pooled in these high-quality enterprises, which will accelerate the survival of the fittest and the upgrading and optimization of industrial structure objectively. Meanwhile, once the industry investment fund can obtain a good return on investment, it will produce the effect of gathering resources and capital, and promote more resources and social capital to flow to the industry guidance fund, so as to expand the social investment, improve the efficiency of capital allocation, and promote economic growth.

\section{Problems in the Operation of Industry Guidance Fund}

\subsection{SWOT Analysis}

Combined with the current situation of the development of government industry guidance fund in China, we use SWOT model to analyze the strengths, weakness, opportunities and threats of government industry guidance fund.

\subsubsection{Strengths Analysis}

The small and medium-sized enterprises generally have the problems of small scale and insufficient liquidity, which are not able to meet the requirements of 
bank loans and bond issuance, and the financing problem is prominent. By establishing the government industry guidance fund, taking corresponding measures to guide, it ensures the government and social funds to invest in strategic leading industries and emerging industries.

In addition, China's fixed asset investment is about 63.53 trillion yuan, and the private fixed asset investment is 39.41 trillion yuan (see Figure 4), accounting for $62 \%$ in 2018 (see Figure 5). It can be seen that the private investment plays an important role in China's economic development. According to the guidance of government industry development, more professional private equity investment funds are selected as limited partners to participate in investment

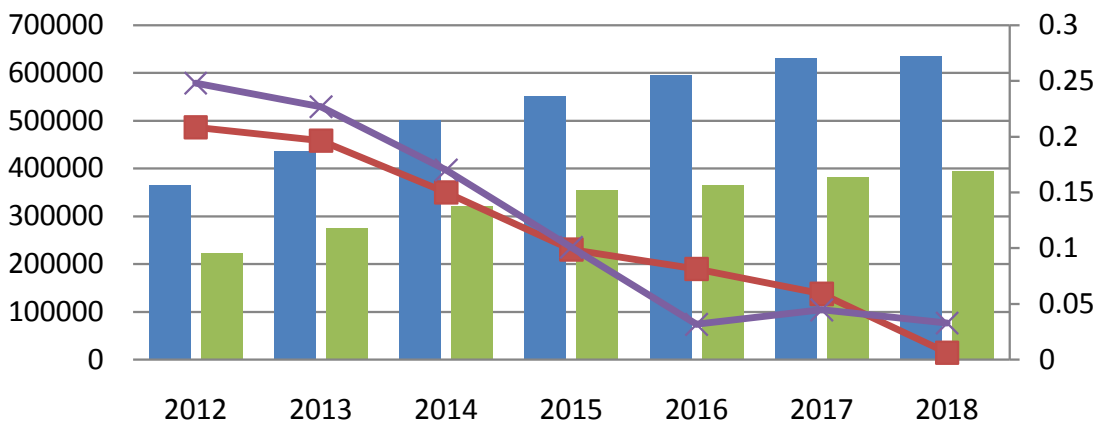

\section{Private fixed asset investment \\ - Growth rate of fixed asset investment in the whole society \\ $\leftarrow$ Growth rate of private fixed asset investment}

Figure 4. Investment in fixed assets of whole society and the private sector ${ }^{4}$.

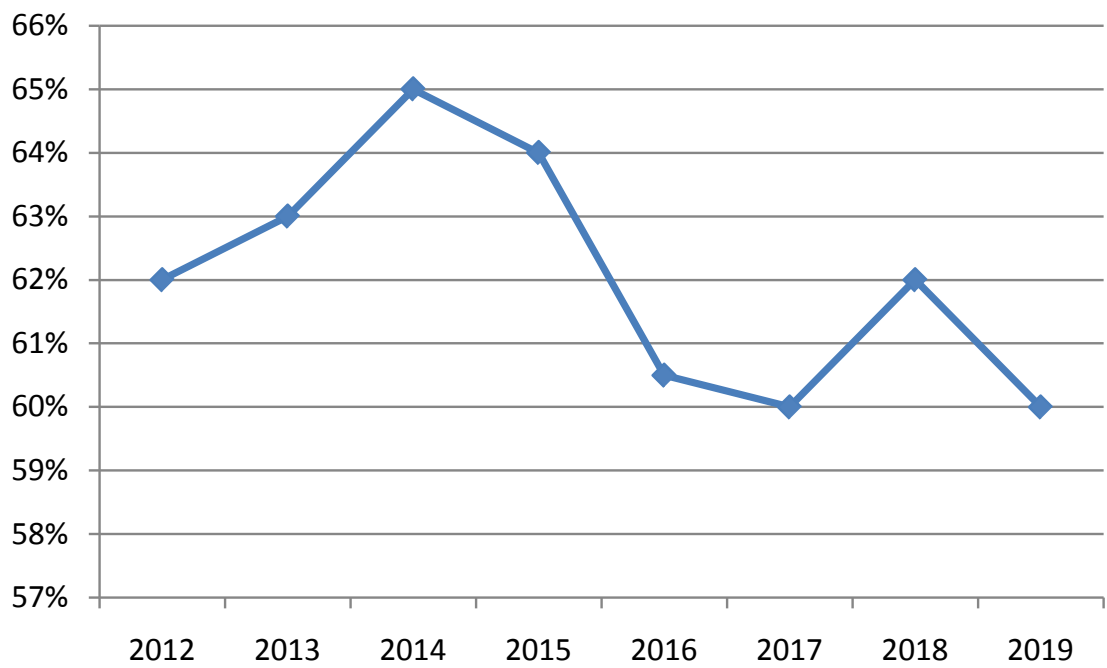

Figure 5. Proportion of private fixed assets investment in fixed assets investment of whole society ${ }^{5}$.

${ }^{4}$ Source: http://www.stats.gov.cn/.

${ }^{5}$ Source: http://www.stats.gov.cn/. 
rather than directly investment in private enterprises, which avoids the crowding out effect to some extent.

\subsubsection{Weakness Analysis}

With the rapid growth of the number and scale of government industry guidance fund, the problems that affect the operation efficiency are becoming more and more prominent. See 4.2 Analysis of operation problems for details.

\subsubsection{Opportunities Analysis}

The outline of the 13th five year plan of China proposes that: we should optimize the modern industrial system, implement the strategy of building a strong manufacturing country, and support the strategic innovation Promote industrial development and accelerate the development of service industry with high quality and efficiency. All these have created good conditions for the development of industry investment fund. In recent years, the downward pressure on China's economy has gradually increased. The government needs to explore new economic growth points vigorously. China has entered a critical period of economic and industrial restructuring. With the deepening of the reform of taxation, financial and other reforms, it will also become a golden period to accelerate the development.

\subsubsection{Threats Analysis}

On June 4, 2019, the U.S. Department of Commerce issued a notice to launch the second anti-dumping and anti-subsidy sunset review and filing investigation on stainless steel welded pressure pipes imported from China. Under the background of frequent attention to manufacturing subsidies, the government industrial support may be invisible, and the industry guidance fund might be an important direction of national and policy. On March 22, 2018, the Trump administration of the United States announced that "due to the infringement of intellectual property rights, it will impose $\$ 50$ billion in tariffs on Chinese goods and impose investment restrictions". To some extent, the Chinese government can break the trade barriers set by capitalist countries by guiding external funds to invest in key development areas through the industry guidance fund.

\subsection{Analysis of Operation Problems}

\subsubsection{Difficulties in Raising Funds after the "New Regulations on Asset Management"}

The establishment of the guidance fund is generally $20 \%-30 \%$ of the government's contribution, inciting social capital to jointly establish a fund of funds, and then introducing a high-quality private equity venture fund management agency to jointly launch a sub-fund or participate in its established equity investment fund. In social capital, bank funds are an important source of guidance fund cooperation. On April 27, 2018, the People's Bank of China and four financial regulatory agencies jointly issued the guidance on regulating the asset management business of financial institutions (referred to as the "new regulations on 
asset management"). Although the new regulations clearly stipulate that there are separate provisions for venture capital funds and government industry guidance funds, but in fact, the arrival of the new regulations in 2018 makes funds subject to strict supervision. After the release of the new regulations, it is difficult for bank funds to enter the equity investment field. At the same time, public funds, private equity funds, government platforms and other enterprises cannot be directed into the guidance funds through structured design, which makes it more difficult for the guidance funds to raise funds.

\subsubsection{Coordination of Policy and Commercial Goals}

In terms of development objectives, there are differences between the guidance fund and the cooperative equity investment fund management institutions. The guidance fund mainly plays the role of guiding and leveraging, pursuing the realization of policy objectives, bearing less risk and not aiming at profits. The funds managed by the equity investment fund management institution, which is in cooperation with it, are the aggregation of financial funds and social funds, which is to carry out market-oriented operation and pursue the realization of the commercial goals under the condition of large investment risk, and the ideal investment return is required. This is easy to cause contradictions between different subjects due to the differences in the pursuit of goals, affecting the operation efficiency of the guidance fund.

\subsubsection{Low Capital Utilization}

The low utilization rate of guidance fund is also a relatively prominent problem. The reasons for the idle funds are: first, driven by the policy dividend, some local governments, especially those in underdeveloped areas, have not yet planned the guidance fund operation system. Second, the professional ability of some guidance funds is lacking, and the loss of state-owned assets is strictly prevented, so there is a situation where money is afraid to be spent. Third, there is a lack of high-quality entrepreneurial projects that can be invested in the region. Among them, the lack of investment projects is an important reason. This leads to the guidance fund does not play a leverage role in leveraging social capital, in addition, it is not conducive to the state-owned assets to produce due investment benefits.

\subsubsection{Confusion of Project Evaluation System}

Although it is clearly mentioned in the relevant documents of China's guide fund management measures that the relevant performance evaluation system should be established, the performance evaluation mechanism system of each province and city has not yet been unified. At present, the main performance evaluation method is to apply the past evaluation system of financial expenditure projects, which is not strong in the specific adaptability of guidance fund. In addition, the performance evaluation of the master fund, the sub fund and the invested enterprise is confused by the individual evaluation system, which leads to the confusion of the evaluation system. 


\subsubsection{The Management Ability Is Quite Different among Regions}

The amount of funds is usually large, so it puts forward higher requirements for the ability of management organizations and managers, but the actual management ability varies greatly from place to place. For example, Shenzhen has a high degree of marketization, activity and talent accumulation in the industry. All of these provide favorable conditions for the business development of Shenzhen guidance fund. However, compared with the southwest region, which has a smaller total scale of guidance funds, it is still in a relatively primary stage, with a small number of excellent teams and poor capital market activity. There are fewer sub funds, smaller scale and weaker leverage effect of social capital.

\subsubsection{Imperfect Exit Mechanism}

The exit channels of government industry guidance fund are similar to those of traditional venture capital and private equity investment, mainly including equity transfer, buyback, IPO and other ways [6]. At present, China's multi-level capital market system is still under construction, and the market foundation for the government industry to guide the fund to exit smoothly is insufficient.

In addition, some guidance funds are unwilling to withdraw from the mature projects for the sake of economic benefits. This kind of behavior is not only contrary to the requirements for the benefit of the people, but also has the crowding out effect on social capital, which has not realized the virtuous cycle and rolling use of funds.

\section{Policy Suggestion}

\subsection{Liberalize the Limit on the Proportion of Capital Contribution}

Previously, $20 \%$ - 30\% of the capital contribution ratio has been one of the hard conditions for guidance fund. Few financial contributions are more than $30 \%$, and if $70 \%$ of social capital is not in place in time, it will lead to the waste of financial funds. In solving the problem of the proportion of capital contribution, many local governments have begun to loosen their restrictions. For example, the notice issued by the Tianjin Municipal Government clearly stated that the $30 \%$ quota for the guidance fund will be relaxed. After the release, the guidance fund has more initiative in the use of funds.

\subsection{Constructing a Coordination Mechanism between Policy and Commercial Goals}

In the construction of coordination mechanism, it is suggested that based on the principle of "government guidance, market operation", based on the guidance fund management measures, the policy orientation of the government should be fully reflected in the formulation of the corresponding provisions, so as to ensure that the general direction does not deviate from the goal of policy guidance. Within the framework of the management measures, the market rules are strictly followed and market-oriented operations are carried out. The government does not interfere with the specific operation and management of the specialized eq- 
uity investment fund management institutions it cooperates with, so as to maximize the autonomy of the specialized fund management institutions. According to the regional economic development, the restrictions on reinvestment ratio and investment scope are gradually relaxed, and the market vitality of the fund is further released, and the government's guiding objectives are achieved through market-oriented operation.

\subsection{Reasonably Arrange the Size of the Guidance Fund}

First of all, the government should strengthen macro-planning and reduce blindness when setting up the guidance fund. National and local macroeconomic management departments should play the role of top-level design, decide whether it is necessary to set up guidance funds according to the local industrial characteristics, avoid the repeated investment and waste of resources caused by the establishment of too many guidance funds in various regions, and focus on the funds that have been set up to form an investment and bring benefits as soon as possible. At the same time, the financial department should timely release the number of guidance funds, the amount of financial contribution, the scale of attracting social capital, the field of investment and other data, so as to guide the orderly development of guidance funds in various regions. Secondly, the problem that the investment of the guidance fund is too cautious should be solved by establishing a comprehensive performance evaluation system of guidance fund.

\subsection{Improve Performance Evaluation and Legal System}

The performance evaluation of the fund should not only consider the economic benefits, but also pay attention to the policy benefits. We suggested that the government industry guidance fund can be evaluated from three perspectives of compliance, management and benefits. Firstly, the compliance indicators include the scale of introducing social capital, the proportion of capital invested in start-up enterprises, the proportion of capital invested in small and medium-sized enterprises, etc. The management indicators include the evaluation of the management and fund utilization of the guidance fund; the benefit indicators include the evaluation of the operation effect of the guidance fund and its impact on society, such as the equity investment and development in the region Direct or indirect benefits, employment , contribution to scientific and technological progress brought by the exhibition.

\subsection{Balancing the Pace of Development between Regions}

The central and western regions shoulder more severe historical mission of industrial structure adjustment and have more adjustment space. However, the development of industry guidance fund in these regions is relatively slow. We should give full play to the leverage effect of the central and western government guidance fund and optimize the administrative procedures, guide the industry investment fund to invest in the development of the central and western regions, 
strengthen the allocation function of the industry guidance fund to the two production factors of capital and employment, so as to promote the adjustment of industrial structure through the transmission mechanism at the macro level.

\subsection{Building a Multi-Level Exit Channel}

The policy guide should spread the accumulated stock pressure of A-share IPO exit, develop and deepen the exit of M \& A, so as to unblock the exit channel of industry investment fund and accelerate the capital turnover to invest in more potential enterprises. Besides, improving the follow-up fund-raising of the industry and the market confidence of investors, and promoting the release of the macro effect of the industry investment fund through the promotion of the total investment amount and the efficiency of fund use. In addition, various types of equity market operation entities should be vigorously developed, including equity trading center, equity custody trading center, etc. By providing small and medium-sized enterprises with all-round and multi-level services such as new three board listing, share reform and reorganization, financial and legal advice, etc., can it provide smooth channels and efficient ways for the government to guide the smooth withdrawal and circular development of the fund.

\section{Conclusions}

In conclusion, China's economy is in a critical period of economic restructuring and upgrading of traditional industries. Therefore, it is particularly important for the government to provide sufficient support to the competitive field through the establishment of industry guidance fund. Due to the increasing difficulties in raising funds for industry guidance funds, the difficult coordination between the government and the market, the lack of high-quality entrepreneurial projects available for investment in the region, the confusion of project evaluation system and the large gap in regional management ability, these make the operating efficiency of the guidance fund face some difficulties. The government needs to pay great attention to the above problems and actively seek solutions.

This paper makes a detailed analysis of the development model of the industry guidance fund, and points out the guiding role of the government in the development of the industry guidance fund. Through research, it is concluded that in the aspect of optimizing the operating efficiency of industry guidance funds, we should pay attention to broadening the source channels of industry guidance funds, properly handling the relationship between the government and the market, reasonably arranging the size of the industry guidance funds, improving performance evaluation and legal system, balancing the development pace of the industry guidance funds between regions, and building a multi-level exit channel of industry guidance funds.

\section{Supported}

Supported by 2016 Social Science Planning and Cultivation Project (2016PY42) 
and the Central University Basic Research Business Expense Project (SWU1909314).

\section{Conflicts of Interest}

The authors declare no conflicts of interest regarding the publication of this paper.

\section{References}

[1] China Venture. (2019) Research Report on the Government Industry Investment Fund in 2019. CV Source Database of China Venture Group.

[2] Liu, G.M. (2019) Government Industry Investment Funds: Organizational Form, Functional Mechanism and Development Performance. Public Finance Research, 7, 71-76.

[3] Yan, A. and Hübner, F.L. (2015) How Does Governmental versus Private Venture Capital Backing Affect a Firm's Efficiency? Evidence from Belgium. Journal of Business Venturing, 30, 4. https://doi.org/10.1016/j.jbusvent.2014.11.001

[4] Zhang, Z.L. (2018) Research on the Economic Effect and Action Path of the Government Investment Fund. Chinese Academy of Fiscal Sciences.

[5] Guo, P.S. (2017) Analysis on the Mechanism of Government Guidance Fund to Promote the Optimization of Industrial Structure. Economic \& Trade Update, 27, 62-65.

[6] Yuan, M.C. (2017) Research on Withdrawal of Government Industry Guidance Fund. Chinese Academy of Fiscal Sciences. 